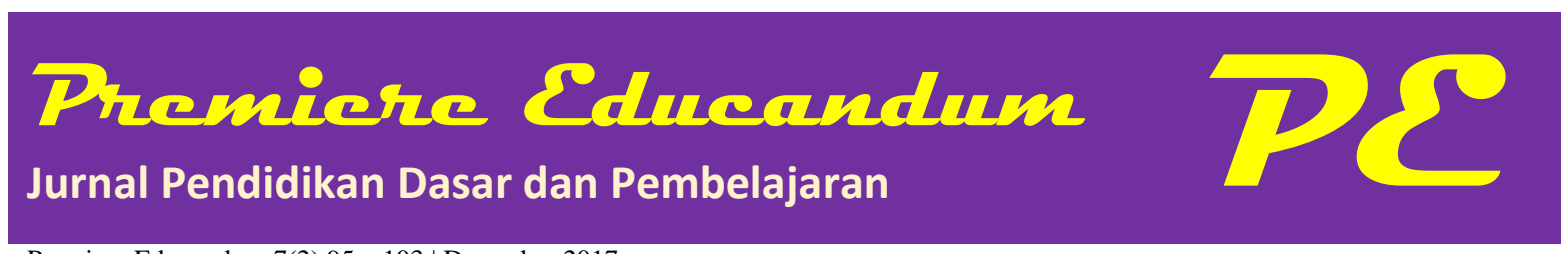

Premiere Educandum 7(2) 95 - 103 | Desember 2017

Copyright @2017 Universitas PGRI Madiun

ISSN: 2088-5350 (Print) / 2528-5173 (Online)

Available at: http://e-journal.unipma.ac.id/index.php/PE

DOI: $10.25273 /$ pe.v7i2.1468

\title{
Strategi Implementasi Model Pembelajaran Kooperatif Tipe Jigsaw Di Kelas IV Sekolah Dasar
}

\author{
Harli Trisdiono $^{1)}$, Istutik Zuwanti ${ }^{2)}$ \\ ${ }^{1}$ LPMP D.I. Yogyakarta \\ email: harli_tris@yahoo.co.id \\ ${ }^{2}$ SD Negeri Godean, Sleman, D.I. Yogyakarta \\ email: iszu2803@gmail.com
}

\begin{abstract}
The aim of this research is to know the implementation strategy of jigsaw type cooperative learning model in elementary school, activity improvement, and student learning outcomes. The study used a type of class action research in second cycle. Each cycle is done in two meetings. The subjects of this research are the students of Grade IVA of Godean I State Elementary School, Godean District, Sleman Regency. The subject is 34 students, consisting of 17 male students and 17 female students. The object of research is subjects of Natural Sciences (IPA). The results showed that the implementation of jigsaw type cooperative learning in elementary school requires careful preparation. Preparations include appropriate material selection, understanding of student characteristics, the formation of heterogeneous expert groups, observations and mentoring during discussions in expert groups and jigsaw groups directly followed up, and additional learning resources. Implementation of appropriate implementation strategy of jigsaw type cooperative learning can improve student activity and learning outcomes.
\end{abstract}

Keywords: jigsaw type cooperative learning, SD science, student activity, student learning outcomes

\section{Abstrak}

Penelitian ini bertujuan untuk mengetahui strategi implementasi model pembelajaran kooperatif tipe jigsaw di sekolah dasar, peningkatan aktivitas, dan hasil belajar siswa. Penelitian menggunakan jenis penelitian tindakan kelas dua siklus. Masing-masing siklus dilakukan dalam dua pertemuan. Subjek penelitian adalah siswa kelas IVA SD Negeri Godean I, Kecamatan Godean, Kabupaten Sleman. Subjek siswa sebanyak 34, terdiri dari 17 siswa laki-laki dan 17 siswa perempuan. Objek penelitian adalah mata pelajaran Ilmu Pengetahuan Alam (IPA). Hasil penelitian menunjukkan bahwa implementasi pembelajaran kooperatif tipe jigsaw di sekolah dasar memerlukan persiapan yang matang. Persiapan yang dilakukan antara lain pemilihan materi yang cocok, pemahaman karakteristik siswa, pembentukan kelompok ahli yang heterogen, pengamatan dan pendampingan selama diskusi di kelompok ahli dan kelompok asal yang langsung ditindaklanjuti, dan sumber belajar tambahan. Penerapan strategi implementasi pembelajaran kooperatif tipe jigsaw yang tepat dapat meningkatkan aktivitas dan hasil belajar siswa.

Kata Kunci: pembelajaran kooperatif tipe jigsaw, IPA SD, aktivitas siswa, hasil belajar

\section{A. PENDAhULUAN}

Pembelajaran IPA mempunyai karakteristik yang berhubungan dengan cara mencari tahu tentang alam secara sistematis (Djojosoediro, W., 2011:20), sehingga IPA bukan hanya penguasaan kumpulan pengetahuan yang berupa fakta-fakta, konsep-konsep, atau prinsipprinsip saja tetapi juga merupakan suatu proses penemuan. Pembelajaran IPA mencakup materi yang cukup luas sehingga untuk menyelesaikan target ketuntasan belajar siswa, perlu perencanaan dan pelaksanaan 
pembelajaran yang matang. Diperlukan suasana pembelajaran yang menyenangkan dengan penggunaan metode dan strategi yang tepat, sehingga siswa akan merasa tertarik dan dapat memperkuat kemampuan kognitif, afektif dan psikomotor serta tujuan pembelajaran IPA di sekolah dasar dapat tercapai.

Hasil belajar IPA siswa kelas IV SDN Godean I, Sleman, D.I. Yogyakarta pada tengah semester I Tahun Ajaran 2016/2017 masih rendah. Rendahnya prestasi ini dapat dilihat sdari banyaknya siswa yang mendapat nilai di bawah Kriteria Ketuntasan Minimal (KKM), yaitu sebanyak 22 (65\%). Salah satu penyebab rendahnya prestasi siswa disebabkan oleh siswa cenderung segan untuk bertanya kepada guru jika menghadapi kesulitan memahami materi yang dipelajari. Persoalan masih rendahnya prestasi belajar siswa perlu segera diatasi.

Model pembelajaran kooperatif tipe jigsaw adalah model pembelajaran yang menitikberatkan kepada kerja siswa dalam bentuk kelompok kecil. Siswa berdiskusi dalam kelompok ahli dan kelompok asal. Ketika siswa mengalami kesulitan, dalam diskusi kelompok siswa dapat bertanya kepada temannya. Hal ini dapat melatih siswa mempunyai keberanian untuk bertanya. Kemampuan bertanya siswa yang semakin baik, diharapkan dapat meningkatkan keefektifan proses pembelajaran. Melalui penerapan model pembelajaran kooperatif tipe Jigsaw diharapkan dapat meningkatkan hasil belajar IPA pada siswa Kelas IV SD Negeri Godean I semester II tahun ajaran 2016/2017.

\section{B. METODE PENELITIAN}

Penelitian dilakukan pada bulan April sampai Juni 2017 dengan subjek penelitian siswa kelas IVA SD Negeri Godean I, Kecamatan Godean, Kabupaten Sleman. Objek penelitian adalah mata pelajaran Ilmu Pengetahuan Alam (IPA). Subjek siswa sebanyak 34, terdiri dari 17 siswa laki-laki dan 17 siswa perempuan.

Penelitian ini dilakukan dengan menggunakan metode penelitian tindakan kelas yang terdiri dari 2 siklus. Penelitian dilakukan bersama antara peneliti 1 , dan peneliti 2 sebagai guru pelaksana pembelajaran. Penelitian ini dilakukan untuk mengambil data: (1) hasil pengamatan selama pembelajaran, dan (2) nilai siswa. Pengamatan dilakukan untuk mengetahui keterlaksanaan pembelajaran dengan menggunakan model pembelajaran kooperatif tipe jigsaw.

Analisis data keterlaksanaan pembelajaran dilakukan dengan pendekatan kualitatif deskriptif. Analisis data ini dilakukan dengan cara merefleksikan hasil pengamatan dan hasil tes evaluasi siswa. Pengamatan terhadap pelaksanaan diskusi pada kelompok ahli dan asal dilakukan untuk mengetahui keefektifan pelaksanaan model jigsaw. Wardani, Wihardit dan Nasution (2002:87), Rusman (2011:218), Martinis Yamin (2013:91) menjelaskan bahwa pelaksanaan pembelajaran menggunakan metode kooperatif tipe jigsaw akan efektif apabila: terdapat kerjasama, tanggungjawab anggota kelompok, saling percaya, semua anggota aktif.

Berdasarkan syarat keefektifan pelaksanaan model jigsaw tersebut, maka instrumen pengamatan proses pembelajaran dikembangkan dengan 
aspek pengamatan: 1) memberi masukan materi diskusi, 2) mendengarkan penjelasan anggota lain, 3) mencatat hasil diskusi, 4) mengemukakan pendapat, 5) memberi respon pendapat anggota lain, 6) tidak mendominasi diskusi, 7) berdiskusi dengan baik. Masing-masing aspek diberi skor dari rentang 1 sampai 5 . Skor maksimal 35. Penghitungan skor yang diperoleh menggunakan rumus:

$$
\text { skor }=\frac{\text { skor yang diperoleh }}{\text { skor maksimal }} \times 100
$$

Siswa dikatakan aktif dalam mengikuti pembelajaran jika mempunyai rentang skor sebagai berikut: >80 sangat aktif, $70-80$ aktif, 60-70 kurang aktif, $<60$ tidak aktif. Hasil analisis keaktifan siswa dikomparasi dengan hasil belajar siswa dan diskripsi tiap siklus menjadi simpulan terhadap strategi implementasi penggunaan model pembelajaran kooperatif tipe jigsaw di sekolah dasar.

Analisis terhadap hasil belajar dilakukan dengan memberikan test di akhir siklus. Kriteria ketuntatasan minimal (KKM) menjadi tolok ukur keberhasilan tindakan. KKM yang ditetapkan adalah 70. Tindakan dinyatakan berhasil apabila $70 \%$ siswa telah mencapai atau melampaui KKM.

\section{HASIL DAN PEMBAHASAN}

Hasil Penelitian

Pembelajaran dilaksanakan dalam dua siklus. Masing-masing siklus dilaksanakan dalam dua kali pertemuan. Alokasi waktu setiap pertemuan 2 x 35 menit. Tahap pelaksanaan setiap siklus terdiri dari: 1) perencanaan, 2) pelaksanaan pembelajaran, 3) pelaksanaan observasi atau pemantauan, dan 4) refleksi (Rochiati Wiriaatmadja,
2008:66). Perencanaan pada siklus 1 dilakukan sebagai tindak lanjut dari kondisi hasil analisis pra tindakan. Perencanaan pada siklus berikutnya merupakan tahap perbaikan atas pelaksanaan pembelajaran pada siklus sebelumnya.

Hasil Siklus 1

Materi pembelajaran pada siklus 1 adalah daur hidup padi. Perencanaan pembelajaran pada siklus satu adalah menyusun perangkat pembelajaran dan instrumen penelitian. Perangkat pembelajaran terdiri dari rencana pelaksanaan pembelajaran (RPP), alat peraga pendidikan, bahan ajar pendukung, lembar kerja siswa, dan instrumen test.

Pembagian kelompok (asal dan ahli) pada siklus 1 diserahkan sepenuhnya kepada siswa. Siswa membagi diri dalam 7 (A sampai G) kelompok asal. Masing-masing kelompok terdiri dari 5 anggota, kecuali kelompok F terdiri dari 4 anggota. Masing-masing anggota bergabung dalam kelompok ahli yang terdiri dari 5 (1 sampai 5) kelompok.

Hasil pengamatan terhadap hasil diskusi pada siklus 1 di masing-masing kelompok ahli dan asal tersaji pada tabel 1.

Salah satu tugas anggota kelompok ahli adalah memandu diskusi di kelompok asal sesuai dengan materi yang dipelajari di kelompok ahli. Ketidakaktifan mengikuti diskusi di kelompok ahli berdampak pada penguasaan materi yang kurang maksimal. Tabel 1 menunjukkan bahwa masih ada 3 orang siswa yang tidak aktif berdiskusi di kelompok ahli. hal lain yang menjadi catatan selama diskusi di 
kelompok ahli adalah belum semua siswa membuat catatan.

Tabel 1. Hasil Pengamatan diskusi kelompok ahli siklus 1

\begin{tabular}{lllll}
\hline Klp & SA & A & KA & TA \\
\hline 1 & 5 & 1 & 1 & 0 \\
\hline 2 & 3 & 1 & 2 & 1 \\
\hline 3 & 3 & 2 & 2 & 0 \\
\hline 4 & 3 & 3 & 0 & 1 \\
\hline 5 & 2 & 2 & 1 & 1 \\
\hline
\end{tabular}

Keterangan: $\mathrm{SA}=$ sangat aktif, $\mathrm{A}=$ aktif, $\mathrm{KA}$ $=$ kurang aktif, $\mathrm{TA}=$ tidak aktif.

Siswa yang tidak aktif di kelompok ahli berdampak pada diskusi di kelompok asal. Hal ini dibuktikan dengan hasil pengamatan diskusi di kelompok asal.

Tabel 2. Hasil Pengamatan diskusi kelompok asal siklus 1

\begin{tabular}{lllll}
\hline Klp & SA & A & KA & TA \\
\hline A & 1 & 2 & 1 & 1 \\
\hline B & 0 & 2 & 2 & 1 \\
\hline C & 1 & 1 & 1 & 2 \\
\hline D & 1 & 1 & 2 & 1 \\
\hline E & 2 & 2 & 1 & 0 \\
\hline F & 1 & 1 & 1 & 2 \\
\hline G & 0 & 1 & 1 & 2 \\
\hline
\end{tabular}

Tabel 2 menunjukkan bahwa masih ada siswa yang tidak aktif saat diskusi di kelompok asal. Pengamatan pada kelompok C, F, dan G memberikan hasil bahwa anggota yang tidak aktif dipengaruhi oleh kemampuan pemandu diskusi. Ketika pemandu diskusi kurang menguasai materi yang disebabkan ketidakaktifannya selama diskusi di kelompok ahli, maka diskusi menjadi tidak dinamis.

Pengamatan terhadap kerjasama dalam diskusi di kelompok (ahli dan asal) menunjukkan bahwa pada waktu ada anggota yang tidak aktif atau kurang aktif, anggota lain belum memberikan bantuan yang maksimal. Demikian juga pada waktu ada anggota yang masih asyik berkegiatan sendiri, anggota lain kurang memberikan motivasi.

Hasil tes sebagai evaluasi di akhir siklus 1 tersaji pada tabel 3 .

Tabel 3. Hasil belajar siswa siklus 1

\begin{tabular}{lll}
\hline Hasil & Jumlah & persentase \\
\hline$<$ KKM & 12 & 35,29 \\
\hline$\geq$ KKM & 22 & 64,71 \\
\hline
\end{tabular}

Kekurangefektifan diskusi pada kelompok asal berdampak pada capaian hasil belajar yang belum maksimal. Baru $64,71 \%$ siswa yang mencapai dan/atau melampaui KKM.

Beberapa penyebab belum maksimalnya keefektifan dan hasil belajar pada siklus satu, yaitu: a) kelompok yang dibentuk siswa masih berdasarkan pertemanan, sehingga heterogenitas pada kelompok ahli belum tercapai; b) jalannya diskusi pada kelompok ahli belum maksimal; c) masih ada anggota kelompok ahli yang belum membuat catatan secara baik yang berdampak pada tidak maksimalnya ahli dalam memandu diskusi di kelompok asal; d) kerjasama pada diskusi di kelompok asal masih kurang, sehingga pada saat memandu diskusi kurang lancar, cenderung belum ada sumbangan yang signifikan dari anggota lain untuk memperdalam materi; e) bantuan selama diskusi belum maksimal.

\section{Hasil Siklus 2}

Hasil refleksi siklus 1 digunakan untuk perencanaan siklus 2. Perbaikan tindakan pada siklus 2 dilakukan agar pembelajaran lebih efektif dan hasil 
belajar meningkat. Perbaikan yang dilakukan pada siklus dua yaitu: a) perbaikan pada pembentukan kelompok asal sehingga homogen, yang berdampak pada keanggotaan kelompok ahli menjadi heterogen; b) optimalisasi diskusi pada kelompok ahli dengan meningkatkan frekuensi intervensi guru agar diskusi semakin optimal; c) mewajibkan semua anggota kelompok ahli membuat catatan dan menjadikan catatan sebagai salah satu bentuk penilaian; d) menjelaskan kembali bahwa keaktifan anggota pada diskusi kelompok asal menjadi salah satu jenis penilaian.

Tahap perencanaan pada siklus 2 dimaksimalkan dengan melakukan persiapan lebih matang. Setiap langkah pembelajaran sesuai dengan tahapan pembelajaran kooperatif tipe jigsaw kemabli didiskusikan. RPP disusun lebih jelas sehingga setiap kemungkinan yang terjadi pada waktu pembelajaran dapat semaksimal mungkin diantisipasi.

$$
\text { Pada tahap pelaksanaan }
$$
pembelajaran, dilakukan perbaikan pada pembetukkan kelompok dan pendampingan secara lebih intensif. Guru lebih maksimal dalam mengamati jalannya pembelajaran. Pada saat diskusi kelompok kurang lancar, guru melakukan intervensi agar diskusi dapat berjalan lancar.

Pengamatan terhadap tindakan pada siklus 2 menunjukkan bahwa pembelajaran berjalan lebih baik. Hasil pengamatan terhadap hasil diskusi di masing-masing kelompok ahli sebagai berikut:

Tabel 4. Hasil Pengamatan diskusi kelompok ahli siklus 2

\begin{tabular}{lllll}
\hline Klp & SA & A & KA & TA \\
\hline 1 & 5 & 2 & 0 & 0 \\
\hline
\end{tabular}

\begin{tabular}{lllll}
\hline 2 & 4 & 3 & 1 & 0 \\
\hline 3 & 6 & 1 & 0 & 0 \\
\hline 4 & 6 & 1 & 0 & 0 \\
\hline 5 & 4 & 2 & 0 & 0 \\
\hline
\end{tabular}

Keterangan: $\mathrm{SA}=$ sangat aktif, $\mathrm{A}=$ aktif, $\mathrm{CA}$ = cukup aktif, $\mathrm{TA}=$ tidak aktif.

Pelaksanaan diskusi pada kelompok ahli sudah semakin baik. Semua siswa aktif berdiskusi. Hasil wawancara dengan siswa yang kurang aktif berdiskusi memberi informasi karena siswa tersebut kurang melakukan persiapan.

Diskusi di kelompok asal juga sudah semakin baik. Tabel 5 menggambarkan keaktifan siswa saat diskusi di kelompok asal pada siklus 2 .

Tabel 5. Hasil Pengamatan diskusi kelompok asal

\begin{tabular}{lllll}
\multicolumn{5}{c}{ siklus 2 } \\
\hline Klp & SA & A & KA & TA \\
\hline A & 4 & 1 & 0 & 0 \\
\hline B & 4 & 1 & 0 & 0 \\
\hline C & 3 & 2 & 0 & 0 \\
\hline D & 5 & 0 & 0 & 0 \\
\hline E & 2 & 3 & 0 & 0 \\
\hline F & 2 & 2 & 1 & 0 \\
\hline G & 3 & 1 & 0 & 0 \\
\hline
\end{tabular}

Jalannya diskusi di kelompok asal yang semakin baik berdampak pada pencapaian hasil belajar. Persentase siswa yang mencapai atau melebihi KKM meningkat. Tabel 6 menunjukkan hasil belajar siswa pada siklus 2 .

Tabel 6. Hasil belajar siswa siklus 2

\begin{tabular}{lll}
\hline Hasil & Jumlah & persentase \\
\hline$<$ KKM & 3 & 8,82 \\
\hline$\geq$ KKM & 31 & 91,18 \\
\hline
\end{tabular}

Pembahasan

Strategi pembelajaran dengan menggunakan model pembelajaran 
kooperatif tipe jigsaw sangat dipengaruhi oleh kematangan persiapan guru dalam memfasilitasi pembelajaran. Persiapan yang dilakukan guru yaitu menyiapkan perangkat dan pendukung pembelajaran. Beberapa aspek yang dipersiapkan dengan lebih baik yaitu: pemilihan materi, strategi pembentukan kelompok, penjelasan cara belajar dengan model jigsaw, penyiapan lingkungan yang kondusif, pemantauan kelompok, dan pendampingan kelompok pada waktu belajar (Mengduo \& Xiaoling, 2010).

Pemilihan dan penyiapan materi pada siklus 1 sudah cukup baik. Hal ini dapat dilihat pada hasil belajar pada siklus 1 yang cukup baik, dengan 64,71\% siswa mencapai atau melampaui KKM. Faktor yang mempengaruhi masih adanya siswa yang belum mencapai KKM adalah adanya 3 siswa yang tidak aktif saat diskusi di kelompok ahli, sehingga pada saat memimpin diskusi di kelompok asal kurang maksimal.

Pemahaman guru pada karakteristik siswa sangat berperan dalam proses pembelajaran (M. Syahran Jailani \& Abdul Hamid, 2016). Pemahaman karakter atau kompetensi siswa yang harus dipetakan dalam pembelajaran kooperatif tipe jigsaw antara lain: 1) kemampuan mencatat, 2) kemampuan memimpin diskusi, 3) kemampuan verbal. Pembentukan kelompok pada siklus 1 yang diserahkan kepada siswa, berdampak pada kurang optimalnya diskusi. Tabel 2 menunjukkan ada 9 siswa yang tidak aktif, dan 9 siswa yang kurang aktif.

Salah satu kunci dari pembelajaran kooperatif tipe jigsaw adalah pendalaman materi pada waktu diskusi di kelompok ahli. Masing-masing kelompok ahli membahas materi yang berbeda. Hasil diskusi di kelompok ahli dibawa ke kelompok asal untuk didiskusikan bersama. Dengan kata lain, anggota kelompok ahli menjadi ahli pada materi tertentu dan memimpin kelompok asal untuk memahami materi tersebut. Berdasar karakter pembelajaran kooperatif tipe jigsaw ini, maka heterogenitas di kelompok ahli sangat penting. Hal ini agar diskusi dan pendalaman materi di kelompok ahli berjalan dengan baik. Karakteristik siswa digunakan dalam membentuk kelompok asal, sehingga diskusi pada kelompok ahli dapat berjalan dengan baik, karena ketika anggota kelompok asal membentuk kelompok ahli, karakter yang dibutuhkan untuk memperlancar diskusi dapat tercapai.

Pada siklus 1, pendampingan/ intervensi guru belum maksimal karena didorong untuk memberikan peran lebih kepada siswa dalam belajar kelompok. Pengamatan siklus 1 menunjukkan bahwa terdapat kelompok ahli dan asal yang belum bekerja secara maksimal. Terdapat 3 siswa anggota kelompok ahli yang tidak aktif berdiskusi. Hal ini berakibat pada kelancaran diskusi di kelompok asal. Perbaikan dilakukan pada siklus 2, dengan melakukan pemantauan dan pendampingan secara lebih intensif. Hasil pengamatan segera ditindaklanjuti dengan memberikan bimbingan dan dorongan agar semua anggota kelompok aktif berdiskusi, dan masing-masing anggota memberi dorongan kepada anggota lain untuk aktif.

Model jigsaw sangat tergantung dari heterogenitas kelompok ahli. Pembentukan kelompok asal sebagai basis pembentukan kelompok ahli, harus benar-benar homogen, sehingga berdampak pada heterogenitas kelompok 
ahli. Kelompok ahli yang heterogen, berdampak pada masing-masing kelompok terdapat siswa yang mempunyai karakteristik masing-masing yang mendinamisasi diskusi di kelompok ahli. Diskusi yang dinamis dan berjalan dengan baik pada kelompok ahli, berdampak pada penguasaan materi dapat optimal. Penguasaan materi yang baik berdampak pada saat anggota kembali ke kelompok asal. Masing-masing anggota mempunyai bekal penguasaan materi yang cukup baik.

Proses pembelajaran pada siklus 1 tidak dapat optimal disebabkan belum terpenuhinya syarat-syarat penggunaan model pembelajaran. Pembentukan kelompok asal dilakukan siswa, yang berakibat pada karakteristik masingmasing kelompok asal yang cenderung heterogen. Perbaikan tindakan dilakukan pada silus 2 dengan memperbaiki kelemahan yang terjadi pada siklus 1 .

Kelompok dibentuk berdasarkan analisis karakteristik siswa. Siswa dikelompokkan dengan memperhatikan karakter masing-masing. Ketika kelompok asal homogen, maka kelompok ahli menjadi heterogen. Diskusi di kelompok ahli pada siklus 2 menjadi lebih baik. Masing-masing kelompok ahli ada anggota yang mempunyai kecepatan dalam menguasai materi. Siswa yang cepat dalam penguasaan materi, menjadi penggerak jalannya diskusi. Pada masingmasing kelompok ahli juga ada anggota yang mempunyai kemampuan baik dalam membuat catatan hasil diskusi. Ketika selesai diskusi, catatan masing-masing kembali dibahas. Siswa yang pandai dalam membuat catatan memandu masing-masing anggota untuk menyempurnakan catatan. Catatan yang dibuat menjadi bahan bagi masing- masing anggota ketika kembali ke kelompok asal dan memandu diskusi.

Peran guru dalam mendinamiskan diskusi kelompok ditingkatkan. Pada siklus 1, guru lebih berperan sebagai pengamat. Peran pengamat menjadikan intervensi diskusi kelompok kurang. Hal ini mengakibatkan ada beberapa kelompok tidak masimal dalam berdiskusi. Pengamatan guru pada siklus 2 ditindak lanjuti dengan memberikan bimbingan agar diskusi kelompok berjalan dengan baik. Ketika ada kelompok yang diskusinya terhenti, guru menyampaikan pertanyaan pemancing agar diskusi dapat kembali berlangsung. Anggota kelompok dengan kemampuan memimpin diskusi yang baik, guru melalui anggota kelompok tersebut memberikan stimulus agar diskusi dapat lebih baik lagi. Intervensi guru juga dilakukan dengan memotivasi dan mengingatkan anggota kelompok lain untuk mendorong anggota kelompok yang kurang aktif.

Siklus 1 sumber belajar siswa masih sangat terbatas. Siswa masih mengandalkan buku teks pelajaran. Perbaikan pada siklus 2 dilakukan dengan persiapan yang lebih matang. Pembentukan kelompok dilakukan sebelum pembelajaran dimulai. Masingmasing siswa sudah diberitahu bagian materi yang akan didiskusikan di kelompok ahli. Dampak dari persiapan ini adalah siswa sudah mencari sumber belajar tambahan dari internet, buku di perpustakaan, dan sumber lain.

Beberapa perbaikan tindakan pada siklus 2 memberikan dampak pada meningkatnya keaktifan dan hasil belajar siswa, perbandingan siklus 1 dan 2 tersaji pada tabel 7 dan tabel 8 . 
Tabel 7. Perbandingan keaktifan siswa pada siklus 1 dan siklus 2

\begin{tabular}{lllll}
\hline \multirow{2}{*}{ Hasil } & \multicolumn{2}{l}{ Siklus 1} & \multicolumn{2}{l}{ Siklus 2} \\
\cline { 2 - 5 } & jml & $\%$ & jumlah & $\%$ \\
\hline SA & 6 & $17,65 \%$ & 23 & $67,65 \%$ \\
\hline A & 10 & $29,41 \%$ & 10 & $29,41 \%$ \\
\hline KA & 9 & $26,47 \%$ & 1 & $2,94 \%$ \\
\hline TA & 9 & $26,47 \%$ & 0 & $0,00 \%$ \\
\hline
\end{tabular}

Hasil penelitian ini menunjukkan bahwa keaktifan siswa meningkat dari siklus 1 ke siklus 2. Hasil penelitian ini sejalan dengan hasil penelitian Yalvema Miaz (2015).

Tabel 8. Perbandingan Hasil belajar siswa pada siklus 1 dan siklus 2

\begin{tabular}{lllll}
\hline \multirow{2}{*}{ Hasil } & \multicolumn{2}{l}{ Siklus 1} & \multicolumn{3}{l}{ Siklus 2} \\
\cline { 2 - 5 } & jml & $\%$ & jumlah & $\%$ \\
\hline$<$ KKM & 12 & 35,29 & 3 & 8,82 \\
\hline$\geq$ KKM & 22 & 64,71 & 31 & 91,18 \\
\hline
\end{tabular}

Tabel 8 menunjukkan bahwa hasil belajar siswa pada siklus 2 meningkat dibanding siklus 1. Dengan kata lain, model pembelajaran kooperatif tipe jigsaw dapat meningkatkan hasil belajar siswa. Hasil penelitian ini sejalan dengan temuan yang diperoleh Kilic (2008); Widiastini, Kusmariyatni, \& Arini (2014); Liando (2014).

\section{SIMPULAN}

Implementasi pembelajaran kooperatif tipe jigsaw di sekolah dasar memerlukan persiapan yang matang. Persiapan yang dilakukan antara lain pemilihan materi yang cocok, pemahaman karakteristik siswa, pembentukan kelompok ahli yang heterogen, pengamatan dan pendampingan selama diskusi di kelompok ahli dan asal yang langsung ditindaklanjuti, dan sumber belajar tambahan. Penerapan strategi implementasi pembelajaran kooperatif tipe jigsaw yang tepat dapat meningkatkan aktivitas dan hasil belajar siswa.

\section{DAFTAR RUJUKAN}

Djojosoediro, W. (2011). Retrieved Juni 21, 2017, from Pengembangan Pembelajaran IPA SD: http://pjjpgsd.unesa.ac.id/mod/ page/view.php?id=49

Jailani, M. S., \& Hamid, A. (2016). Pengembangan Sumber Belajar Berbasis Karakter Peserta Didik (Ikhtiar optimalisasi Proses Pembelajaran Pendidikan Agama Islam (PAI)). Nadwa. Jurnal Pendidikan Islam Vol. 10, Nomor 2,, 175-192.

Kilic, D. (2008). The effect of the jigsaw techniqueon learning the concepts of the principles and methods of teaching. World Applied Sciences Journal 4 (Supple 1) , 109 - 114.

Liando, M. R. (2014). Penerapan model pembelajaran kooperatif tipe jigsaw untuk meningkatkan hasil belajar. Jurnal Ilmiah Cisoc (Kajian Rumpun Pendidikan Ilmu Sosial) Volume 1 No. 01, 77 - 88.

Martinis Yamin. (2013). Strategi dan Metode dalam Model Inovasi Pembelajaran. Jakarta: Gaung Persada Press Group.

Mengduo, Q., \& Xiaoling, J. (2010). Jigsaw Strategy as a Cooperative Learning Technique: Focusing on the Language Learners. Chinese Journal of Applied Linguistics (Bimonthly) Vol. 33 No. 4, 113 125.

Miaz, Y. (2015). Improving Students' Achievement of Social Science By Using Jigsaw Cooperative Learning 
Model at Primary School. IOSR Journal of Research \& Method in Education Volume 5, Issue 4 Ver. II (Jul - Aug. 2015), 01-07.

Rochiati Wiriaatmadja. (2008). Metode penelitian tindakan kelas untuk meningkatkan kinerja guru dan dosen. Bandung: Remaja Rosdakarya.

Rusman. (2011). Model-model pembelajaran: Mengembangkan profesionalisme guru. Jakarta: PT Raja Grafindo Persada.

Wardani, I., Wihardit, K., \& Nasution, N. (2002). Penelitian Tindakan Kelas. Jakarta : Universitas Terbuka.

Widiastini, M., Kusmariyatni, N., \& Arini, N. W. (2014). Keefektifan model pembelajaran kooperatif tipe jigsaw untuk meningkatkan hasil belajar IPS Siswa kelas V. Journal Mimbar PGSD Universitas Pendidikan Ganesha Jurusan PGSD Vol: 2 No: 1. 